\title{
Container repositioning management in liner shipping industry
}

\author{
Nasser Saeidi ${ }^{a}$, Hassan Jafari ${ }^{b^{*}}$, Ali Ameli ${ }^{\mathrm{b}}$ and Narges Zaersoleymani ${ }^{\mathrm{c}}$
}

${ }^{a}$ Senior Lecturer in Economics, Faculty of Maritime Economics and Management, Khoramshahr University of Marine Science and Technology, Khoramshahr, Iran

${ }^{b}$ M.A student in Marine Transportation, Faculty of Maritime Economics and Management, Khoramshahr marine science and technology university, Khoramshahr, Iran

${ }^{c}$ M.A. student in Marine Transportation, Pardis, Khoramshahr marine science and technology university, Khoramshahr, Iran

\section{H R O N I C L E}

Article history:

Received January 16, 2013

Received in revised format

23 April 2013

Accepted 29 April 2013

Available online

May 12013

Keywords:

Container

Combined model

Empty container repositioning

Container flow transportation

\begin{abstract}
A B S T R A C T
Managing empty containers in shipping industry plays an important role to increase the profitability on marine shipping industry. This paper presents an empirical investigation to detect influential factors in container transportation and estimates the value of empty containers transportation. The study also evaluates and compares different strategies employed to reduce the charge of empty container transportation. By selecting three major passages including Trans-pacific, trans-Atlantic and Europe-Asia and considering the balance in transportation network, regardless of the origin of shipping companies, an optimistic estimation of empty container transportation would be possible; therefore, empty container transportation could be explained, quantitatively. Furthermore, since shipping companies organize the movement of containers in various routes, four different strategies are also proposed.
\end{abstract}

(c) 2013 Growing Science Ltd. All rights reserved.

\section{Introduction}

During the past few years, there have been big concentration on moving commodities using containers and it is estimated that nearly containers transport $60 \%$ of goods worldwide. Container has revolutionized goods transportation, and has substantially decreased the cost of goods transportation in ports and other regions. The increase in world trade, after 1980, has relatively speedup the process of containerization. There is an approximate rate of $10.2 \%$ for the growth of container usage, which is well above the world's annual GDP growth. One of the main reason is because of the availability of ships with the capacity of, at least, 12000 TEU, which has reshaped the transportation network to hub-and-spoke and it has increased the quantity of containers transported to main ports. World trade faces imbalance, which further causes movement of empty containers such as the existence of empty containers route to China.

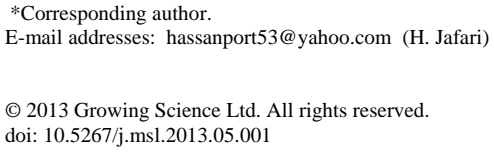


In 2003, container traffic, from Asia to Europe, increased ten times more than the opposite direction. In 2004, about half of transported containers to Northern Europe, returned empty. Drewry, as a consulting agent, estimated that, from 1993 on, the transportation of empty containers has been about $20 \%$ of all oceanic transportations. Based on reports in 2003, the cost of empty container transportation has been less than fifteen million dollars, which accounts for $27 \%$ of running cost of fleets in all over the world.

\section{Literature review}

Potts (1970) and White (1972) are believed to be the first who presented network models for empty container management. Florez (1986) formulated a dynamic container allocation problem as a profit optimization problem with network structure, which could be solved by standard networks algorithms. Florez (1986) presented a profit optimization model for the problem of empty container repositioning and leasing for ocean-going ships. He discussed the sensitivity of the model to the length of the planning horizon, and reported that the solution of the case study could be slightly influenced by the changes in the length of planning horizon. However, he noted that this conclusion could not be generalized to other cases because the determination of an adequate planning horizon depends on the concentration of activities in the network under consideration.

Dejax and Crainic (1987) made a literature review concerning empty vehicle movements. They stated that, although this topic had received much attention since the sixties, poor consideration had been dedicated to the development of original models addressing the container transportation issue specifically. They mentioned only a few works addressing the problem of allocating empty containers from a surplus terminal to a demanding terminal, using linear programming formulations in a deterministic and dynamic approach.

Crainic, et al. (1989) discussed the problem of locating empty vehicles in an intercity freight transportation system in order to minimize the cost of depot opening and vehicle transportation, while satisfying client demand. Since this problem belongs to a strategic planning level, that addresses long-term decision, they did not consider the space-time dependency of events. Dejax et al. (1992) presented a model for a combined container routing-vehicle itinerary building model and explained that the planning horizon could be long enough to incorporate the next set of arrivals and departures, and to permit the consistent, and system wide building of vehicle itineraries. Labor contracts, safety regulations, etc. could limit the actual length of vehicle itineraries and planning horizon.

Crainic et al. (1993) presented some models for empty container allocation and distribution between a land transportation and international maritime shipping network. They stated that, to get valid solutions, the length of planning horizon and the end-of-horizon conditions have to be estimated, very carefully. In real-life applications, it is recommended some limitation for the length of planning horizon since the number of decision variables in any period is relatively large. The information available on the future supply and demand of empty containers must be considered when selecting the proper length of the planning horizon. To specify the end-of-horizon conditions, they recommended forcing reasonable figures for the empty container stocks in each depot at the end of planning horizon or incorporating a salvage value term in the holding cost functions for the last period to consider for containers at each depot.

Russell and Urban (1993) studied the impacts of forecast length and accuracy in extending the planning period beyond the frozen horizon of rolling production schedules. They compared the performance of the Wagner-Whitin method and the Silver-Meal heuristic for various lengths and accuracy of horizon extensions. The experimental results revealed that horizon extension was worthwhile for relatively large forecast errors and that Wagner-Whitin could improve in more cases than previously thought. 
De Matta and Guignard (1995) studied lot-sizing and changeover decisions in production schedules used on a rolling horizon basis. They tested the impacts of the length of planning horizon, the starting inventory, and the demand fluctuation on all schedules. They reported that the changeover expenditure decreases, while the holding cost increases when the planning horizon is extended. They also demonstrated that beyond a certain length of planning horizon, the savings in the annual production cost would be minimized. Shen and Khoong (1995) concentrated on the business perspective of the shipping industry, developed a decision supporting system for the dynamic reallocation of empty containers, which was capable of minimizing repositioning expenditures and provided decisions covering leasing and returning containers from external sources.

Cheung and Chen (1998) compared a two-stage stochastic model with a two-stage deterministic model for the dynamic empty container allocation problem. They performed some experiments with rolling horizons and stated that a longer planning horizon would not necessarily better than a shorter one. When the planning horizon is lengthened, solutions in some of the test cases could be improved. Nevertheless, solutions in other test cases could become worse. They did not give any discussion on other factors such as differences in the number of ports, the number of voyages, and the transportation times between ports, which might explain the observations.

Jiele (1999) investigated the empty container allocation problem for the single commodity case with min cost flow algorithm and multi-commodity variance based on the adaptation of linear programming technique. In the latter case, the author took also considered two container types having the same size. Some experimental results indicated a meaningful relationship between problem size and run time. Choong et al. (2002) studied the planning horizon problem for the tactical management of a homogeneous fleet of empty containers. They developed an integer programming technique and compared a 15-day model to a 30-day model. They also concluded that the application of a longer planning horizon usually gives better distribution of empty containers, encouraging the implementation of slow and cheap modes. Olivo et al. (2005) highlighted the relevance of empty container management in the current trend of world-wide trade and presented a mathematical model to support carriers’ decisions using hourly resolution over a weekly planning horizon.

More recently, Chang et al. (2008) presented a heuristic technique to provide an optimal solution to reduce the cost of empty container interchange. Using available data, they examined the effectiveness of computational time and solution quality. Imai et al. (2009) studied the optimization problem for container shipping network design, proposing a technique to solve the empty container repositioning problems. In this work, the port calling sequence and empty container repositioning were examined simultaneously by designing the objective function with a penalty cost factor. Thus, the problem was integrated and formulated as a two-stage problem. The idea of adding penalty expenditure in the proposed model and applying virtual points in designing networks structure could be certainly valuable. Di Francesco et al. (2009) proposed a multi-scenario, multi-commodity, time-extended optimization model to deal with empty container repositioning problem. Some uncertain parameters in the model, which could not be forecasted through historical data, were considered as sets of a limited number of values, according to shipping company opinions.

Bandeira et al. (2009) proposed a decision support system (DSS) to handle full and empty container trans-shipment operations. The arrangement of repositioning empty containers could be determined by adjusting several parameters in the DSS model. Tuga'sgroup (2002) investigated the conditions of empty containers in Los Angeles and Long Beach, in a report to Gateway Cities. Recognizing and documenting empty container flow channel in two ports, Los Angeles and Long Beach. Contacting and interviewing specialists in container transportation to propose a precise definition of empty container transportation chain, exposing limitations and discovering potential opportunities to optimize the chain, studying the possibility of establishing an informational system based on internet to facilitate the process of container transportation between road and rail transport vehicles, ship owners and other employees in container transportation chain. 


\section{Factors influencing the repositioning of empty containers}

In recent years, there have been growing interests in the cooperation among the foreign owners to acquire an effective operation in transporting the containers and lowering the cost. A few managerial systems have provided transportation agents and shipping lines with containers via the third party supplier. The imbalance in trade acts as the primary source of empty container repositioning, which further explains that trade in one direction outweigh the other direction. Passages in Pacific Ocean and Asia-Europe are remarkably out of balance (Chang et al., 2008). According to UNCTAD's reports, in 2005 the amount of trade from Asia to US was 13.9 million TEU, while the opposite passage saw a trade of 4.3 million TEU. Other facts than imbalance also might have impact on repositioning of empty containers (Choong et al., 2002). These factors are dynamic movement, unclear transportation demand, diversity of tools, blind regions in transportation chain and daily strategic affairs of transportation officials. Unscheduled and unknown affairs could be counted as other influential factors, which expose the unpredictable components in system. These factors might be created by customer demands such as unloading, combination, repositioning and maintenance. For example, the industrial flow and movement in a port might results in the change of programs of container-ship. In addition, climate condition and traffic jam levels up the transportation time. Such uncertain affair provokes delay in arrival of full containers and unplanned empty containers (Denis et al., 2009; Song \& Carter, 2009). Furthermore, unclear demand is the most frequent phenomenon. In the big competitive shipping market, goods owners are superior, and thus, shipping companies often encounter unpredicted demands. Therefore, shipping firms, in order to remove unpredicted demands, must carry out extra capacity and effective repositioning.

\section{Four strategies for flow balancing-based empty container repositioning}

Empty container management could be categorized into effective internal management and efficient external management, and enhanced management in operational and strategic level in the shipping line field could optimize the former one (Denis et al., 2009). Enhancing the latter one materialized whenever a significant cooperative mechanism happens among other shipping, like sharing containers, ships and the management of demand chain. Therefore, we may use two criteria to implement different strategies, which are internal cooperation and incorporation of containers from external shipping companies. In an ideal situation, balanced trade demands must not include empty containers repositioning, and unbalanced trade demands have to be minimized. In other words, empty container repositioning cost could be minimized by balancing container flow in the world transportation level. To evaluate the strategies, we may use a mathematical program. Therefore, we begin by introducing the following symbols in order to formulate the empty container repositioning problem.

$\mathrm{N} \quad$ Number of zones in transportation network

L $\quad$ Number of shipping lines

$\mathrm{d}_{\mathrm{jk}}^{\mathrm{i}} \quad$ The amount of annual demand from zone $\mathrm{j}$ to $\mathrm{k}$ for shipping $\mathrm{i}$

$\mathrm{C}_{\mathrm{j} k}^{\mathrm{i}} \quad$ The cost of repositioning of an empty container from $\mathrm{j}$ to $\mathrm{k}$ for shipping $\mathrm{i}$

$\mathrm{x}_{\mathrm{jk}}^{\mathrm{i}} \quad$ Number of repositioned containers from $\mathrm{j}$ to $\mathrm{k}$ for shipping $\mathrm{i}$

$\mathrm{K}_{\mathrm{j}} \quad$ Indicator of a shipping route from $\mathrm{j}$ to $\mathrm{k}$

Due to the fact that shipping companies coordinate container flow over various routes, or are interested in sharing containers with other firms; the following four different strategies could be designed:

1) Sharing containers with coordinated routes,

2) Sharing containers without coordinated routes,

3) Coordinating routes without sharing containers,

4) Not sharing containers and coordinating routes, 
In this paper, only the first strategy will be discussed.

$\min \sum_{i} \sum_{j} \sum_{k} c_{i j k} x_{i j k}$

subject to

$I_{i j}+x_{i j k}=I_{k j}+x_{i k j}$

$x_{i j k} \geq 0$.

The first condition shows that all input $\left(I_{i j}\right)$ and output flows $\left(I_{k j}\right)$ from zone $j$ are equal. Under this strategy, shipping lines, have almost reached to a mixture of container flow all over the network. We assume that all the data including demand and repositioning cost are available, and container supply is managed, properly. This strategy is a logical ideal analogy, in which empty container repositioning cost have been minimized by balancing the container flow between shipping lines. It is worth to mention that this strategy is impossible due to two reasons. 1- The competition running among shipping companies. 2- World transportation is very complex, and a number of shipping lines coordinate various routes by using Track and Trace system, and have provided adequate containers distribution along the transportation network, and when are in urgent need of container, would hire.

\section{Evaluating four strategies and estimating the amount of empty containers}

This section employs the above four strategies in three transportation routes in order to compare their cost and amount of empty container repositioning. The goal is to evaluate their advantages and to determine the amount of empty container repositioning. This would help us determine the state and progress of reserving empty container performance. Main container route, in Europe-Asia transportation network, is passing the Pacific and Atlantic Ocean. This three shipping routes service three major regions: Asia, US and Europe, which means N3. In this section, we first discuss existing historical records, and reshape them based on our discussion and analysis, and then assess various strategies for managing and handling empty container; at the end results will be reported.

\section{Data Design}

Demand of container exchange from 2003 to 2007 has been represented in Table 1 as follows,

Table 1

Demand of container exchange in three major shipping routes based on US\$/TEU

\begin{tabular}{|c|c|c|c|c|c|c|}
\hline & \multicolumn{2}{|c|}{ Trans-Pacific } & \multirow{2}{*}{\multicolumn{2}{|c|}{$\begin{array}{c}\text { Europe-Asia } \\
\text { Europe-Asia Asia-Europe }\end{array}$}} & \multicolumn{2}{|c|}{ Transatlantic } \\
\hline & Asia-USA & USA-Asia & & & USA-Europe & Europe-USA \\
\hline \multicolumn{7}{|c|}{ 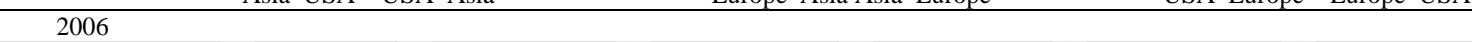 } \\
\hline Fourth quarter & 1878 & 825 & 825 & 1709 & 1009 & 1815 \\
\hline Change (\%) & -1.5 & 1.2 & 1.2 & -3.9 & 7.9 & 5.2 \\
\hline First quarter & 1836 & 815 & 793 & 1454 & 995 & 1829 \\
\hline Change (\%) & -2.2 & -1.2 & -3.9 & -14.9 & -1.4 & 0.8 \\
\hline Second quarter & 1753 & 828 & 804 & 1408 & 1010 & 1829 \\
\hline Change (\%) & -4.5 & 1.6 & 1.4 & -3.2 & 1.5 & 0 \\
\hline Third quarter & 1715 & 839 & 806 & 1494 & 1041 & 1854 \\
\hline Change (\%) & -2.2 & 1.3 & 0.2 & 6.1 & 3.1 & 1.4 \\
\hline Fourth quarter & 1671 & 777 & 792 & 1545 & 1066 & 1762 \\
\hline Change (\%) & -2.6 & -7.4 & -1.7 & 3.4 & 2.4 & -5.0 \\
\hline \multicolumn{7}{|l|}{2007} \\
\hline First quarter & 1643 & 737 & 755 & 1549 & 1032 & 1692 \\
\hline Change (\%) & -1.7 & -5.1 & -4.7 & 0.2 & -3.2 & -4 \\
\hline Second quarter & 1675 & 765 & 744 & 1658 & 1067 & 1653 \\
\hline Change (\%) & 1.9 & 3.8 & -1.4 & 7.0 & 3.4 & -2.3 \\
\hline Third quarter & 1707 & 780 & 777 & 1952 & 1115 & 1725 \\
\hline Change (\%) & 2 & 2 & 4 & 18 & 4 & 4 \\
\hline Fourth quarter & 1707 & 794 & 905 & 2054 & 1147 & 1766 \\
\hline Change (\%) & 0 & 2 & 16 & 5 & 3 & 2 \\
\hline \multicolumn{7}{|l|}{2008} \\
\hline First quarter & 1725 & 861 & 968 & 2021 & 1193 & 1700 \\
\hline Change (\%) & 1 & 8 & 7 & -2 & 4 & -4 \\
\hline Second quarter & 1837 & 999 & 1061 & 1899 & 1326 & 1652 \\
\hline Change (\%) & 6 & 16 & 10 & -6 & 11 & -3 \\
\hline
\end{tabular}


Containerization International Review publishes transportation cost in major commercial routes. This transportation cost is the average cost of transportation in the market retrieved from six shipping companies. From these three-month transportation cost, we have obtained a year average which enables us gaining the transportation cost from 2003 to 2007. It is necessary to mention that presented transportation cost at Table 2 do not precisely show an empty container repositioning cost, since the net profit margin of net sales have been included in transportation cost. We also can lower the transportation cost for the evaluation of more precise cost. For ease of data-collection, we directly consider the transportation expenditure as the repositioning cost. Such treatment does not impact on the performance of these models and it might minimize the advantages of these four strategies. On the other hand, from a commercial point of view, repositioning of an empty container equates with the loss of a full container profit. In addition, the transportation cost of a full container is the same as an empty container. We also, assume that, various shipping lines have the same cost-structure, because the transportation cost basically relies on geographical distance. Table 2 represents the data of $C_{i j k}$.

Table 2

Goods Transportation cost in three major shipping routes based on US\$/TEU

\begin{tabular}{rrrrrrr}
\hline & \multicolumn{2}{c}{ Trans-Pacific } & \multicolumn{2}{c}{ Europe-Asia } & \multicolumn{2}{c}{ Transatlantic } \\
& Asia-USA & USA-Asia & Europe-Asia Asia-Europe & USA-Europe & Europe-USA \\
\hline 2003 & 833 & 1777 & 1573 & 749 & 1391 & 869 \\
2004 & 816 & 1896 & 1772 & 742 & 1442 & 801 \\
2005 & 803 & 1874 & 1769 & 816 & 1646 & 907 \\
2006 & 815 & 1744 & 1475 & 799 & 1819 & 1028 \\
2007 & 769 & 1683 & 1803 & 795 & 1709 & 1090 \\
\hline
\end{tabular}

In this paper, we consider an environment with several world shipping transportation lines, which are cooperating with each other. Due to difficulties in accumulating the amount of cargo transported by each shipping line, we estimate the cargo transported by each shipping transportation line, principally, by analyzing the given exchange according to shipping transportation capacity.

First, for world shipping transportation lines, the capacity often means that they transport more cargoes. Second, based on the existing records, ship cargo components, in various ships of one route, are totally different from each other. However, it is necessary to mention that the transported cargo does not accord with their capacities. Therefore, we introduce an accidental criterion deviance for the cargoes which shows the difference.

Let $\mathrm{V}_{\mathrm{i}}$ be the transportation capacity of cargo ship $i$. We assume that all volume of exchange in these three major shipping routes have been transported using 20 top-level shipping transportation line. This assumption could be proved by the fact that this 20 cargo shipping company accounts for world most important marine transportation network. These twenty companies cover $70 \%$ of transportation in 2007 and occupy three major shipping transportation routes. While small cargo ships usually concentrate on intercontinental or short distances. There is one way to overcome this problem by defining a virtual cargo ship, which indicates the remained transportation components. Thus, we have $\mathrm{L}=20$. The whole transportation costs averages have been represented in Table 3 in 10 samples. These results cover the whole costs of empty container repositioning at three major routes under the related managerial strategies and Table 3 summarizes the results of our experience.

\section{Table 3}

Total costs of empty container repositioning under four strategies

\begin{tabular}{cccccccc}
\hline Year & Strategy1 & reduction\% & Strategy2 & reduction\% & Strategy3 & reduction\% & Strategy4 \\
\hline 2003 & 6965 & $27 / 18$ & 7891 & $40 / 7$ & 7390 & $28 / 13$ & 8522 \\
2004 & 9550 & $34 / 13$ & 10654 & $3 / 33$ & 9816 & $93 / 10$ & 11021 \\
2005 & 11194 & $41 / 13$ & 12573 & $74 / 2$ & 1488 & $14 / 11$ & 12928 \\
2006 & 12954 & $85 / 12$ & 14574 & $96 / 1$ & 13114 & $78 / 11$ & 14865 \\
2007 & 14097 & $25 / 12$ & 15772 & $83 / 1$ & 14200 & $61 / 11$ & 16066 \\
\hline
\end{tabular}


The whole empty container transportation costs in those three major routes are 97.6, 55.9, 19.11, 95.12 and 10.14 million dollars from 2003 to 2007, respectively. This conclusion is due to the fact that results under the strategy 1 show the most optimistic cost estimation of empty containers, since this strategy assumes coordination and prerequisites of route and containers distribution among all cargo ships in the whole network regardless of other factors like dynamism and uncertainty.

Strategy 4, compared with the strategy 1 from 12 up to 18\%, strategy 3 from 10 up to 13\% and strategy 2 from 8.1 up to $4.7 \%$ conserves the cost. It shows that the coordination of routes is more important than container distribution mechanism when lowering the cost of empty container repositioning in above flows. A brief review on the process over the period 2003-2007 reveals that the empty container repositioning cost increased, principally. We have seen there has been much doubt in the costs, in that period of five years. It indicates the empty container transportation and repositioning cost.

From 2003 to 2007, the acquired lowered amount of triple strategies from strategy 4 is totally decreasing which means that in comparison with strategy 4, route coordination and container distribution, they were less able to lower the empty container repositioning. Regardless of estimated costs, the physical volume of empty container is interesting. As mentioned earlier, there is a dispute over the transportation cost of empty containers. Therefore, it is better to use physical volumes to estimate empty container repositioning. Table 4 represents the whole amount of empty container repositioning obtained by averaging 10 samples. In the same way, the reduction amount columns, shows the empty container repositioning reduction retrieved from triple strategies of strategy 4.

Table 4

Sum of empty container repositioning base on million TEU under four strategies

\begin{tabular}{cccccccc}
\hline Year & Strategy1 & reduction\% & Strategy2 & reduction\% & Strategy3 & reduction\% & Strategy4 \\
\hline 2003 & 48.8 & 83.16 & 66.9 & 26.5 & 03.9 & 45.11 & 20.10 \\
2004 & 90.11 & 14.13 & 40.13 & 19.2 & 28.12 & 34.10 & 70.13 \\
2005 & 90.13 & 34.11 & 40.15 & 77.1 & 24.14 & 17.9 & 68.15 \\
2006 & 00.16 & 22.10 & 60.17 & 25.1 & 18.16 & 23.9 & 82.17 \\
2007 & 10.18 & 68.8 & 60.19 & 11.1 & 21.18 & 11.8 & 82.19 \\
\hline
\end{tabular}

Using similar reasoning, it could be obtained that the amount of all containers repositioning, in three major routes, are at least 5.8, 9.11, 9.13, 0.16 and 1.18 million TEU respectively from 2003 to 2007. Compared with strategy 4, strategy 1 could reduce the empty container repositioning down to 7.8 to $8.16 \%$, strategy 3 from 1.8 to $5.11 \%$ and strategy 2 only from 1.1 to $3.5 \%$. From 2003 to 2007, the sum of empty container repositioning has been basically increasing. Considering strategy 4 as the base, the obtained reduction amount from other three strategies gradually reduces. To better understand the amount of empty container repositioning, it is better to compare full container with empty ones. Table 5, indicates the amount of empty container repositioning, distinct from total repositioning which includes both empty and full container repositioning, under the strategy 1 from 2003 to 2007.

\section{Table 5}

Empty container repositioning verses full container repositioning base on TEU million under the strategy 1

\begin{tabular}{ccccc}
\hline Year & Empty container repositioning & Total volume & loaded container repositioning & Total container repositioning \\
\hline 2003 & 48.8 & 46.21 & 04.31 & 52.39 \\
2004 & 90.11 & 05.25 & 60.35 & 50.47 \\
2005 & 90.13 & 38.26 & 80.38 & 70.52 \\
2006 & 00.16 & 12.27 & 00.43 & 00.59 \\
2007 & 10.18 & 98.27 & 60.46 & 70.64 \\
\hline
\end{tabular}


Table 5 shows that empty container repositioning is about $21 \%$ of the whole containers repositioning for the three major routes in the 2003. This amount would increase up to $28 \%$ by 2007 . These results are based on the strategy 1, which is the most optimistic also. For the other strategies, for instance strategy 2, the amount of empty container repositioning, for the period of 2003 to 2007, is respectively $7.23 \%, 35.27 \%, 41.28 \%, 4.29 \%$ and $61.29 \%$, which is about $2 \%$ more. In addition, if other factors, such as dynamism status and uncertainty, be considered, the amount of repositioning in three major routes would increase.

\section{Discussion}

This paper determined the cost of full and empty container under the four different strategies, quantitatively. The results of investigations have indicated that in reducing empty container repositioning, the route coordination was more useful than container distribution mechanism. This is consistent with the fact that the globalization of the service network paves the way for various routes coordination and lowers the empty container repositioning. The routes where there is a heavy imbalance, all cargo ships have the model of a dearth or surplus of commodities which further implies that for empty container repositioning, time is absolutely tight. The cargo ships instructed us that these ships primarily centralized their coordination of route, internally, then for progressing further, implemented the container distribution strategy. Although, the fact revealed us such commercial awareness that big cargo ships tend to join the container distribution solutions. For small cargo ships or regular non-buoyant carriers, due to lack of world-scale coverage, the container distribution strategy is suitable.

Due to the fact that strategy 1 takes into account the whole coordination of route as well as container distribution strategy among all cargo ships all over the network, it can obtain the most reduction in cost of empty container repositioning. Therefore, the results taken from Table 3 to Table 5, under the strategy 1, represent the most optimistic cost of repositioning, empty container repositioning and the amount of empty container without the whole repositioning. In other words, it is possible to put it as low level when estimating empty container repositioning amount. Strategy 4, perform perfectly in coordinating empty containers with exchange demand of each cargo ship in a route while it neither adopts route coordination nor container distribution mechanism. Indeed, due to existence of other factors, such as dynamic process and uncertainty in demand, repositioning, transportation, equipment type, weaknesses in transportation chain, and shipping lines practical and strategic performances, approaching the best workflow is difficult. Specially, the dynamic nature as well as uncertainty regarding external factors could cause a huge repositioning of empty containers, even in balanced routes. Therefore, the results obtained from strategy 4 should not be taken into account as a top level for empty container repositioning. The cost, amount and size of empty container repositioning is basically increasing within the timespan of this research. Compared with base situation, which is strategy 4, the amount of cost reduction obtained from strategy 1 to 3 is generally decreasing. This indicates the fact that the empty container repositioning grows challenging whenever the current container transportation trade follows unchanged, which is more trade and exchange, unbalances more and more. Nevertheless, the route coordination and container distribution could still play a significant role. Because the decreased percentage of base situation is more than $10 \%$, regarding other factors such as dynamic process and uncertainty of other factors, the profit could be more. In this paper we focused on the four strategies of empty container repositioning and container repositioning. However, we do not discuss the managerial issues regarding the route coordination and container distribution. It is necessary to mention that the implementation of these strategies is highly challenging and complicated. For instance, their implementation requires vast knowledge about connections, which denotes geographical location of containers and its condition, and the activity and occupations of various agents, port officials, consignor and inner transportation companies.

By introducing three major routes across the Atlantic Ocean, Pacific Ocean and the Europe - Asia, for instance, we proved the advantages of this strategy and proposed an algorithm for minimization of 
empty container repositioning. This strategy, which is a combination of route cooperation and container distribution, compared to strategies, which neither use route coordination nor container distribution, could reduce the empty container repositioning from 2003 to 2007 by 12 to $18 \%$. Route coordination is superior to container distribution in empty container repositioning cost reduction. The amount of empty container repositioning, apart from total repositioning, for the period of 2003 to 2007, has been respectively 46.21, 5.25, 38.26, 12.27 and 98.27. These estimations determine the amount of empty container repositioning and indicate its process.

The above discussions, has been principally based on commercial balance analysis among several transportation lines concentrate on the impact of various strategies on empty container repositioning. As mentioned before, apart from the commercial imbalance issue, there are other factors which are influential on the empty container repositioning, which are dynamic process, uncertainty, containers type, and weaknesses in the transportation chain and transporter strategic and practical performances. In order to study the reciprocal effects of these factors in the practical level, a better solution would be proposed for establishing an environment with more management and control. This environment could affect the uncertainty, dynamic performances, competition, logistic strategies and other factors which lead to a certain condition. Reviewing the accomplishment of the tasks within a timespan or implementing the guiding planes enables collecting large amount of information which grants deeper insight into the quantitative relation between significant factors and empty container repositioning.

\section{Conclusion}

This paper discussed the empty containers repositioning issue in a large-scale extent from the standpoint of an ocean liner. The significant factors, impact on the empty container repositioning, have been identified by reviewing the text and observing their industrial performances. We have analyzed the effects of route coordination and container distribution on the empty container distribution in a commercial environment including a few ocean liners, by concentrating on the main causes of empty repositioning. Regarding the accumulation of the empty containers, the main causes of the emergence of intensification of such phenomenon are commercial imbalance, transportation cost imbalance, a new container price verse the restoration cost, the storage high tariff where the empty container demand is high. All the solution, which could be adopted for optimizing the empty container management is changing managerial strategies, changing the pipeline in various regions, changing container logistic, IT-based solutions, solutions based on the container manufacturing technology development. As a result, while it is obvious that route coordination and container distribution mechanism can have an impact on the reduction of empty container repositioning, it could not solve it all. The implementation of this strategy, especially in today's uncertain and dynamic environment, would retain it as a challenging issue.

\section{References}

Bandeira, D. L., Becker, J. L., \& Borenstein, D. (2009). A DSS for integrated distribution of empty and full containers. Decision Support Systems, 47(4), 383-397.

Chang, H., Jula, H., Chassiakos, A., \& Ioannou, P. (2008). A heuristic solution for the empty container substitution problem. Transportation Research Part E: Logistics and Transportation Review, 44(2), 203-216.

Chang, H., Jula, H., \& Ioannou, P. (2008), A Heuristic Solution for the Empty Container Substitution Problem. Transportation Research Part E, 44, 203-216.

Cheung, R.K., \& Chen, C. (1998). A two-stage stochastic network model and solution methods for the dynamic empty container allocation problem. Transportation Science 32, 142-162.

Choong, S.T. Cole, M.H., \& Kutanoglu, E. (2002). Empty container management for intermodal transportation networks. Transportation Research Part E, 38, 423-438.

Crainic, T.G., Dejax, P., \& Delorme, L. (1989). Models for multimode multicommodity location problems with interdepot balancing requirements. Annals of Operations Research, 18, 279-302. 
Crainic, T.G., Gendreau, M., \& Dejax, P. (1993). Dynamic and stochastic models for the allocation of empty containers. Operations Research, 41, 102-126.

Dejax, P.J., \& Crainic, T.G. (1987). A Review of Empty Flows and Fleet Management Models in Freight Transportation. Transportation Science, 21(4), 227-247.

Dejax, P., Benamar, F., Crainic, T.G \& Gendreau, M., (1992). Short term container fleet management: issues, models and tools. In: Proceedings of the 6th World Conference on Transport Research, Lyon, France, 29 June-3 July.

Denis L., Banderia, J.L. \& Borenstein, D. (2009). A DSS for empty container distribution planning, Decision Support System, 15(1), 75-82.

De Matta, R., \& Guignard, M. (1995). The performance of rolling production schedules in a process industry. IIE Transactions, 27, 564-573.

Di Francesco, M., Crainic, T. G., \& Zuddas, P. (2009). The effect of multi-scenario policies on empty container repositioning. Transportation Research Part E: Logistics and Transportation Review, 45(5), 758-770.

Florez, H. (1986). Empty-container repositioning and leasing: an optimization model. Ph.D. dissertation, Polytechnic-Institute of New York.

Imai, A., Shintani, K., \& Papadimitriou, S. (2009). Multi-port vs. Hub-and-Spoke port calls by containerships. Transportation Research Part E: Logistics and Transportation Review, 45(5), 740757.

Jiele, Z. (1999). Empty Container Distribution Problem. UROP Report 6019, School of Computing, National University of Singapore.

Olivo A., Zuddas P., Di Francesco M. \& Manca, A. (2005). An operational model for empty container management. Maritime Economics \& Logistics, 7(3), 199-222.

Russell, R.A \& Urban, T.L. (1993). Horizon extension for rolling production schedules: length and accuracy requirements. International Journal of Production Economics, 29, 111-122.

Potts, R.B. (1970). Movement of empty containers within Australia. Working paper, Operations Research Society of Victoria, Melbourne, Australia.

Shen, W.S., \& Khoong, C.M. (1995). A DSS for empty container distribution planning. Decision Support Systems, 15(1), 75-82.

Song, D.P. \& Carter, J. (2009). Empty Container Repositioning in Liner Shipping. Maritime Policy \& Management, 36 (4), 291-307.

White, W.W. (1972). Dynamic transshipment networks: an algorithm and its application to the distribution of empty containers. Networks, 2(3), 211-236. 